\title{
Aplicação do método do Filtro de Kalman Estendido (EKF) em um modelo matemático não-linear para um sistema de multicorpos rígidos para identificação de parâmetros em análise estrutural de um aerogerador de três pás
}

\author{
Fabio F. Real * \\ Instituto Nacional de Metrologia, Qualidade e Tecnologia, INMETRO \\ 20251-020, Rio de Janeiro, RJ \\ E-mail: ffreal@inmetro.gov.br \\ Thiago G. Ritto \\ Universidade Federal do Rio de Janeiro - Departamento de Engenharia Mecânica \\ 21945-970, Rio de Janeiro, RJ \\ E-mail: tritto@mecanica.ufrj.br
}

\begin{abstract}
RESUMO
Hoje existem propostas e políticas em várias regiões do planeta com metas de adoção de fontes renováveis. Neste contexto, a energia eólica apresenta-se como uma importante fonte em ascensão na geração de energia elétrica, tornando-a cada vez mais competitiva se comparada às fontes convencionais.

Um dos problemas atuais no monitoramento da operação de aerogeradores (turbinas eólicas) é a determinação de parâmetros relacionados à sua estrutura, que se alteram ao longo do tempo. Este trabalho aplica o método do Filtro de Kalman Estendido [2,5] em um modelo matemático não-linear para multicorpos rígidos $[1,4]$ para a identificação dos coeficientes de elasticidade e de amortecimento na análise estrutural de um aerogerador de três pás, a partir de dados de campo tratados.

As equações da dinâmica do sistema de multicorpos rígidos são derivadas das seguintes equações [3]:

$$
\begin{gathered}
\sum F_{\text {ext }}=G_{T}^{\Re} \\
\sum M_{\text {ext }}{ }^{L_{i}}=\dot{H}_{B_{i} / L_{i}}^{\Re}+\left(v_{L_{i}}^{\Re} \times G_{B_{i}}^{\Re}\right)
\end{gathered}
$$

onde $\sum F_{\text {ext }}$ é o somatório das forças externas atuantes no sistema, $G_{T}^{\Re}$ é a quantidade de movimento linear total do sistema, $\sum M_{\text {ext }}{ }^{L_{i}}$ é a somatória dos momentos com relação ao ponto $L_{i}$ de referência do link (associação da pá com a cabeça do rotor), $\dot{H}_{B_{i} / L_{i}}^{\Re}$ a derivada da quantidade de movimento linear da pá em relação ao ponto $L_{i}$ de referência do link, $v_{L_{i}}^{\Re}$ é o vetor velocidade em relação ao ponto $L_{i}$ de referência do link $G_{B_{i}}^{\Re}$ é a quantidade de movimento linear referente à cada pá.

A partir das equações (1) e (2) chega-se a um sistema de equações não-lineares acopladas, onde são desconhecidos os ângulos de deslocamento de cada pá em relação ao sistema fixo de referência e os deslocamentos relativos a dois eixos perpendiculares entre si em relação ao topo da torre.

Foi aplicado o método do Filtro de Kalman Estendido (EKF) para a identificação do coeficiente de elasticidade no sistema de cinco equações não-lineares acopladas a partir de dados experimentais tratados utilizando o software MATLAB. Alguns resultados são mostrados na Figura 1, de (a) até (d).
\end{abstract}




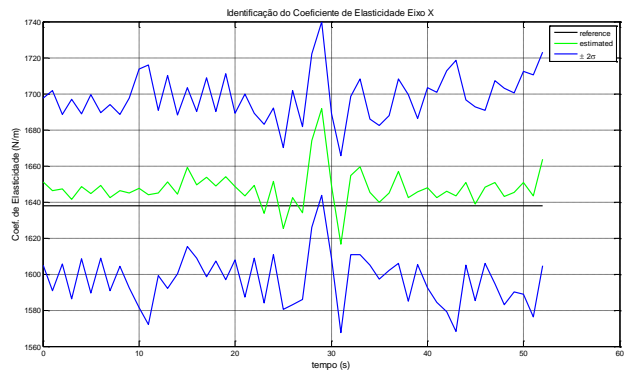

(a)

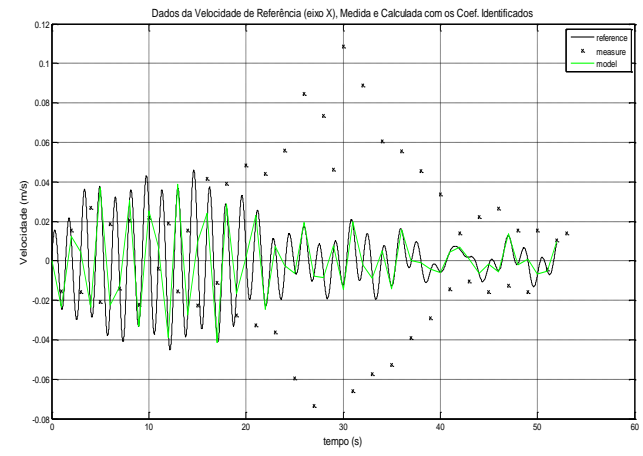

(c)

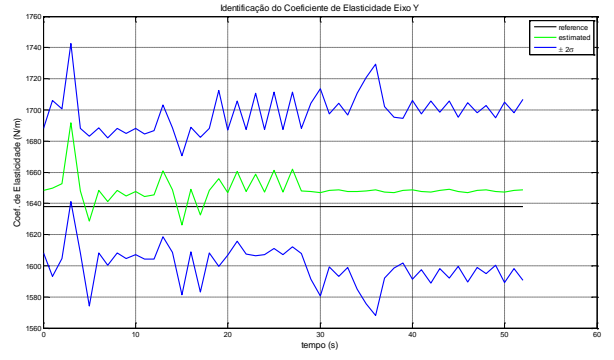

(b)

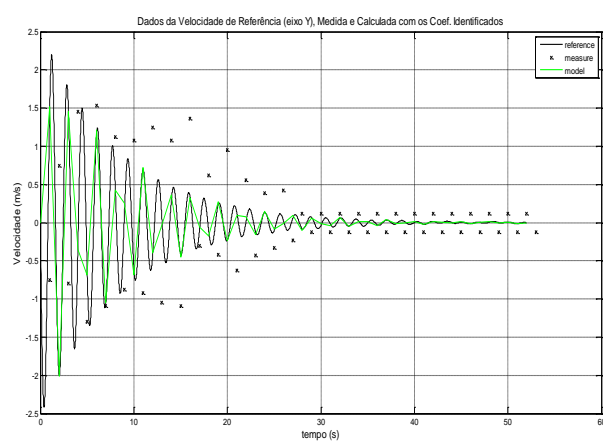

(d)

Figura 1: Identificação do coeficiente de elasticidade na direção $x$ (a) e na direção $y$ (b), sendo o modelo aplicado com os coeficientes identificados na direção $x$ (c) e direção $y$ (d).

Pelas figuras (a) e (b) apresentadas, o método EKF apresentou um bom comportamento para a identificação do coeficiente de elasticidade, uma vez que os valores identificados ficaram próximos ao valor de referência com um desvio padrão aceitável $(2 \sigma)$. As figuras (c) e (d) mostram que os coeficientes identificados aplicados no modelo matemático não-linear mencionado (linha verde - model) acompanha satisfatoriamente a curva de referência (linha preta - reference), com um custo computacional baixo (30 segundos). Com isso é possível aplicar esta metodologia no monitoramento on-line desses coeficientes, já que estes se alteram ao longo do tempo.

Palavras-chave: aerogerador, modelo multicorpos, Filtro de Kalman Estendido

\section{Referências}

[1] C. S. ROBINSON, "Modeling and analysis of helicopter ground resonance utilizing symbolic processing and dynamic simulation software", $\mathrm{Ph}, \mathrm{D}$, thesis, Naval Postgraduate School, 1997.

[2] B. RISTIC, S. ARULAMPALAM, N. GORDON, "Beyond the Kalman Filter: Particle Filters for Tracking Applications", Artech House Radar Library, Boston, 2004.

[3] F. F. Gonzaga, "Modelos computacionais para análise da vibração acoplada rotor-pás com aplicação em turbinas eólicas e ressonância de solo de helicópteros", Projeto de Graduação em Engenharia Mecânica, Universidade Federal do Rio de Janeiro, 2013.

[4] I. F.Santos, C. M. Saracho, J. T. Smith, Contribution to experimental validation of linear and non-linear dynamic models for representing rotor-blade parametric coupled vibrations, Journal of sound and vibration, 271(3-5), pp. 883-904, 2004.

[5] J. KAIPIO, E. SOMERSALO, "Statistical and Computational Inverse Problems", $1^{\mathrm{a}}$ ed., Springer Science+Business Media Inc, Nova Iorque, 2005. 